
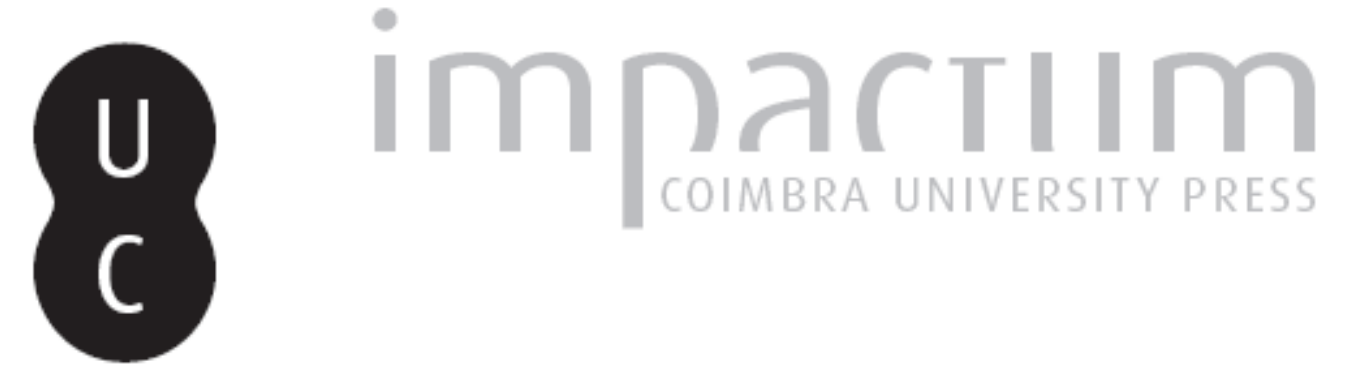

\title{
Moedas hispano-romanas do Monte Figueiró
}

Autor(es): $\quad$ Coutinho, José Eduardo Reis

Publicado por: Imprensa da Universidade de Coimbra

URL persistente:

URI:http://hdl.handle.net/10316.2/45466

DOI:

DOI:https://dx.doi.org/10.14195/1647-8657_34_8

Accessed : $\quad$ 26-Apr-2023 13:39:59

A navegação consulta e descarregamento dos títulos inseridos nas Bibliotecas Digitais UC Digitalis, UC Pombalina e UC Impactum, pressupõem a aceitação plena e sem reservas dos Termos e Condições de Uso destas Bibliotecas Digitais, disponíveis em https://digitalis.uc.pt/pt-pt/termos.

Conforme exposto nos referidos Termos e Condições de Uso, o descarregamento de títulos de acesso restrito requer uma licença válida de autorização devendo o utilizador aceder ao(s) documento(s) a partir de um endereço de IP da instituição detentora da supramencionada licença.

Ao utilizador é apenas permitido o descarregamento para uso pessoal, pelo que o emprego do(s) título(s) descarregado(s) para outro fim, designadamente comercial, carece de autorização do respetivo autor ou editor da obra.

Na medida em que todas as obras da UC Digitalis se encontram protegidas pelo Código do Direito de Autor e Direitos Conexos e demais legislação aplicável, toda a cópia, parcial ou total, deste documento, nos casos em que é legalmente admitida, deverá conter ou fazer-se acompanhar por este aviso.

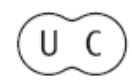


UNIVERSIDADE DE COIMBRA

FACULDADE DE LETRAS

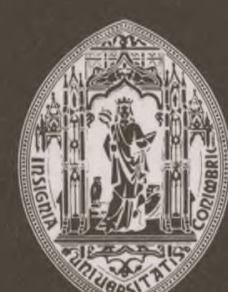

CONIMBRIGA

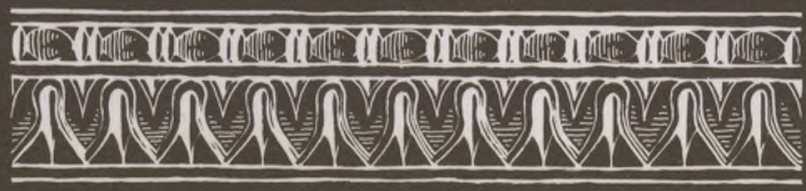

VOLUME XXXIV - 1995

INSTITUTO DE ARQUEOLOGIA 


\section{José EdUARdo REIS COUTINHO}

Licenciado em Teologia

\section{MOEDAS HISPANO-ROMANAS DO MONTE FIGUEIRÓ}

“Conimbriga" XXXIV (1995) p. 191-204

RESUMO: Publicam-se quinze moedas hispânicas encontradas ao acaso das lavras em Monte Figueiró, um castro do concelho de Ansião.

A reduzida área em que as moedas foram recolhidas permite suspeitar de um pequeno tesouro.

ABSTRACT: Fifteen Hispanic coins found by chance when ploughing in Monte Figueiró, a pre-Roman hill-fort in Ansião county, are published here. The reduced area where the coins were found leads to the suspicion they may correspond to a small treasure. 
(Página deixada propositadamente em branco) 


\section{MOEDAS HISPANO-ROMANAS DO MONTE FIGUEIRÓ}

Embora os trabalhos de batida de campo pelo concelho de Ansião se considerem genericamente concluídos, a tarefa de compreensão dos dados obtidos, a sistematização dos materiais encontrados e a coordenação interpretativa daí resultante ainda aguardam algumas ultimações.

De facto, tal cuidado é exigido no âmbito do rigor científico que lhes é devido no enquadramento administrativo de Conimbriga, bem notório pela proximidade geográfica e pelas condições naturais da paisagem.

Uma premente necessidade foi a prospecção, que desvelou novos horizontes à arqueologia da região, fazendo relegar concepções simplistas, cujo motivo radicava na diminuta investigação local. Com vários anos dedicados à pesquisa no terreno, surgiram inúmeros achados de superfície, identificaram-se muitas estações e foi possível recuperar algum espólio já disperso e pronto para venda.

A par do volume de materiais recolhidos em investigações periódicas, existe uma porção complementar que, recentemente, tem vindo a ser desvelada, como é o caso de certos objectos em bronze e cerâmica, por vezes guardados quando razoavelmente conservados e sugestivos.

Reconheceu-se também, pelo contacto com a população dos lugares, o vulgar aparecimento de moedas, das quais se destaca uma pequena quantidade numária hispano-romana, surgida dispersa na proximidade de um muredo(') da plataforma do Monte Figueiró, situado a $18 \mathrm{Kms}$ a SE de Conimbriga.

(') Esta designação é um regionalismo usado para referir os muros mais ou menos alinhados e constituidos com as muitas pedras soltas retiradas do solo nas épocas de lavras. 
Dando notícia dessas moedas descobertas por ocasião de cultivos agrícolas ali levados a efeito até finais de 1978, aquando da preparação das terras para sementeiras de trigo, fica testemunhada a presença de pecúlios monetários ligados à época do domínio romano na região municipal daquela cidade.

Outro aspecto de interesse diz como o achado permite aceder ao conhecimento mais alargado da efectiva circulação de numerário produzido nas oficinas peninsulares e chegado até estes espaços.

\section{O MONTE FIGUEIRÓ}

Este local ${ }^{2}$ ) é a estação arqueológica de maior diversidade material do termo meridional de Conimbriga, pela singularidade manifestada na grande variedade de espólio, desde o Neolítico à Idade Média, numa continuidade de ocupações, que serão futuramente tratadas no momento apropriado.

Morfologicamente, os terrenos adjacentes apresentam a comum característica que configura o núcleo da estrutura principal: à volta dele dispõem-se bacias deprimidas e solos onde o calcário forma tratos salientes e linhas de relevos com estratos à vista no dorso escalvado, o lapiás.

Pobre e densamente pedregoso, ali a topografia cársica salienta a carência de água e a rarefacção das culturas, a vegetação rasteira, esparsa e original, e constitui-lhe o traço mais vigoroso. Todavia, quem

(2) A designação Monte Figueiró deve preferir-se a outras menções toponímicas por ser a mais conforme à tradição, que remonta ao séc.XII:

- Na delimitação de Penela, consignada por carta de foral de Novembro de 1137 , a linha divisória a Poente é indicada pelo circuito que uadit a figueiroa. Cf.PORTUGALIAE MONUMENTA HISTORICA, Leges et Consuetudines, I, Olisipone MDCCCLVI, 374; e SALVADOR DIAS ARNAUT, Ladeia e Ladera, Coimbra 1939, LXXI.

- Nos limites da herdade de Alvorge, doada por Dom Afonso Henriques ao Mosteiro de Santa Cruz de Coimbra, em Fevereiro de 1141, tal menção aparece deveras explícita quando referida per cacumen montis figueirole. Cf. ARQUIVO NACIONAL DA TORRE DO TOMBO, Forais Antigos, maço 12, n. ${ }^{\circ} 3$; e SALVADOR DIAS ARNAUT, op . cit., XX.

Inequivocamente, os compreensíveis arcaísmos designam-no sem a complexidade que o tempo lhe juntou depois da formação do casal estabelecido nas imediações do sopé,a partir do aforamento de 1224.

Conimbriga, 34 (1995) 191-204 
galgar os ásperos declives (3) que o limitam ou subir os carreiros norte e sul - velhos de séculos - que, trilhados, levam à cumeada, encontra, na parte alta, grandes extensões aráveis, apenas molemente onduladas, favoráveis à expansão da agricultura.

A necessidade da população, de há décadas a esta parte, foi chamando à cultura regular de sequeiro aquelas terras elevadas e maninhas, numa tenacidade de aproveitamento agrário, lavrando campos de pedras onde o cereal medra a custo e a oliveira ponteia com geométrica representação pelas encostas de parco desenvolvimento vegetal, mesmo assim utilizado na prática do pastoreio.

Em notável predomínio cresce o tomilho silvestre, o Thymus zygis, vulgarmente conhecido por Erva de Santa Maria; e, das matas de carvalhos de outrora, resta, como veneranda memória, um no cimo do monte e a pequena mancha de exemplares novos junto à povoação de Trás de Figueiró.

Os vestígios arqueológicos de maior representação principalmente mós manuais, pesos de tear, pedaços de dolia, tegulae e cerâmica comum - estendem-se ao longo do planalto, em ligeiro declive segundo o sentido longitudinal, à cota de 370 metros de altitude média, cujo ponto central está referenciado na grandeza 173,75 de longitude e 334,25 de latitude, a partir das coordenadas hectométricas de Gauss, registadas na folha 263 dos Serviços Cartográficos do Exército, à escala de 1/25.000, de 1947.

Este sítio arqueológico pertence à freguesia de Alvorge, concelho de Ansião e distrito de Leiria, e oferece um admirável panorama de largos horizontes visuais.

É, por conseguinte, ponto estratégico dominante a todo o extenso vale agrícola de Póvoa de Pêgas às granjas de Santiago da Guarda, impondo-se eminente pelo seu inconfundível perfil trapezoidal, facilmente identificado na linha de silhuetas orográficas.

Dele se avista Zambujal, Rabaçal, os Germanelos $\left({ }^{4}\right)$, Castelo Ventoso, Alcalamouque, Casas Novas, Rabarrabos, as cristas do

(3) O Monte Figueiró é de acesso muito difícil, impraticável pela encosta do Levante, escarpada, cheia de calhau desprendido dos estratos geológicos; embora menos íngreme nas outras, ambas estão seccionadas por muros, formando socalcos, para aproveitamento dos solos com cultivos adequados.

${ }^{(4)}$ Esta designação medieval, atribuida aos dois montes semelhantes que se elevam na Ladeia, o do castelo de Germanelo e o Jerumelo, tem plena justificação quando são vistos a partir do Monte Figueiró, o único local que os posiciona bem 
Espinhal, Torre de Vale de Todos, Lagoa do Castelo, Monte Alvão, as serranias de Sicó e o povoado de Alvorge.

Como a profundidade dos solos é mínima, devido aos afloramentos rochosos na generalidade do planalto - de si bastante erodido - a realização de trabalhos agrícolas traz à superfície toda a sorte de objectos que o revolvimento das terras vai partindo ou danificando.

Desse modo, qualquer batida efectuada após as lavras do Outono e as colheitas da Primavera foi pródiga em achados colhidos ao longo dos anos.

Os bronzes hispano-romanos agora dados a conhecer foram-nos revelados pelo senhor Augusto Saraiva Luís, de Vale Florido, a quem se devem os contactos com os achadores e a recolha das moedas seguidamente apresentadas.

\section{AS MOEDAS}

O conjunto numismático aqui tratado procede, sem excepção, de achados superficiais que particulares foram reunindo ao longo de várias épocas, por ocasião de trabalhos agrícolas, o que, à partida, lhes retira componentes estratigráficas relacionáveis, que muito contribuiriam para datações precisas.

Os exemplares recolhidos no decurso desses anos somam um total de 15 peças, situadas entre o séc. II a. C. e o governo de Augusto/Tibério, e pertencem a diferentes séries nas cunhagens peninsulares de bronze.

O catálogo é apresentado de acordo com critérios que as aproximam por inscrições no mesmo grupo linguístico: sucessivamente as de escrita fenícia, indígena e latina, entretanto dispostas a partir da alfabetação dos respectivos centros emissores, porque a seriação cronológica torna-se bastante difícil.

$\mathrm{Na}$ identificação das divindades - considerando o sistema religioso dos Fenícios e o culto prestado na então cidade de Gadir prefere-se mencionar Melkart para a representação do exemplar hispano-fenício de Gades, em lugar de Hércules, bem como as do panteão latino nas mais romanizadas.

"germanelos", demonstrando-se, assim, o ponto privilegiado de observação e a singular importância que deteve até à Idade Média.

Conimbriga, 34 (1995) 191-204 
Após a cronologia, igual relevo merecem os dados inerentes ao módulo, peso e eixo, como características físicas distintas.

As referências bibliográficas reportam-se às publicações técnicas de maior implantação nesta matéria e, por vezes, aos artigos específicos que possam elucidar certas perspectivas de grande acuidade.

Finalmente, transfere-se para observações tudo quanto de completivo pareça oportuno neste domínio e seja esclarecedor das datas propostas, principalmente acerca das atribuições sustentadas por distintos autores.

\section{Grupo Fenício}

\section{Gades}

1. As

Á - Cabeça de Melkart, à esquerda, coberta com pele de leão.

Atrás, [clava] sobre o ombro esquerdo.

Orla de pontos.

IÍ - Dois atuns, à esquerda.

Entre as cabeças, crescente externo com ponto central; entre as caudas, a letra fenícia aleph.

Em cima, inscrição fenícia $M P \mathrm{X}$; em baixo, 'GDR.

Orla de pontos.

Cron: Séc. Ili a I a. C.

Mód: 25 mm. Peso: 7,83 gr. Eixo: 10.

Bibl: FERNANDO ALVAREZ BURGOS, La Moneda Hispanica desde sus orígenes hasta el siglo V, Madrid 1992, 167/1050; LEANDRE VILLARONGA, Corpus Nummum Hispaniae Ante Augusti Aetatem, Madrid 1994, 89/57 (5).

Obs: VIVES, 74/1.

GUADÁN, Las Monedas de Gades, n. ${ }^{\circ} 52-58$ (206-45 a.C.), e GIL FARRÉS, La Moneda Hispánica, 1297 (47-44 a. C.).

(5) É dever de justiça exprimir alguns especiais agradecimentos: à Senhora Dr. a Adília Moutinho Alarcão, pela gentileza e disponibilidade do Museu Monográfico de Conimbriga, que limpou e tratou estas moedas; à Senhora Dr.a Maria Isabel Sousa Pereira, pelo salutar acolhimento e notável pedagogia durante anos dispensados sobre estes e demais assuntos da arqueologia; e ao Dr. José da Silva Ruivo, pelas indicações bibliográficas mais recentes e pelo acompanhamento e muitas sugestões prestadas ao longo destes estudos numismáticos. 


\section{Malaca}

2. As

Á- Cabeça barbada de Vulcano, de tipo simples, à direita, coberta com gorro tronco-cónico.

Atrás [tenaz]; à frente, inscrição neo-púnica externa, invertida, $M L K$, bastante sumida.

í( - Busto radiado de Hélio, de frente.

Cron: Séc. II a I a. C.

Mód: 22-21 mm. Peso: 5,43 gr. Eixo: 12.

Bibl: BURGOS, 217/1351; e VILLARONGA, 101/12.

Obs: VIVES, 85/6-7; 86/6, 10, 15; 87/6 (repetidas).

GIL FARRÉS, 1430 (desde 63 a. C.).

\section{Grupo Indígena}

\section{Bevipo}

3. Semis

Á- Duas espigas verticais.

À frente, grafema toponímico $O$.

Orla de pontos.

í( - Hipocampo, à esquerda, e contramarca S.

Orla de pontos.

Cron: Séc. II a I a. C.

Mód: 22 mm. Peso: 5,40 gr. Eixo: 11.

Bibl: BURGOS, 205; e VILLARONGA, 135/12 B.

Obs: A. MARQUES DE FARIA, A Numária de Cantnipo, in Conimbriga (XXVIII) 1989, 94 (séc. II a I a. C.).

4. Semis

Á- Duas espigas verticais.

À frente, grafema toponímico $O$.

í( - Hipocampo, à esquerda, e contramarca S.

Cron: Séc. II a I a. C.

Mód: $19 \mathrm{~mm}$. Peso: 5,94 gr. Eixo: 9.

Bibl: BURGOS, 205; e VILLARONGA, 135/12 B.

Obs: FARIA, 94 (séc. II a I a. C.). 


\section{Bolskan}

5. As

A- Cabeça barbada, à direita.

Atrás, um delfim.

Orla de linha.

íí - Ginete lanceiro, à direita.

Atrás, símbolo astral de cinco pontas.

Em baixo, inscrição ibérica BOLSKAN.

Orla de linha.

Cron: Séc. II a I a. C.

Mód: 24-23 mm. Peso: 8,86 gr. Eixo: 3.

Bibl: BURGOS, 240/1505; e VILLARONGA, 211/8.

Obs: VIVES, 43/4.

6. As

A- Cabeça barbada, à direita.

Atrás, um delfim.

Á - Ginete lanceiro, à direita.

Atrás, símbolo astral de cinco pontas.

Em baixo, inscrição ibérica BOLSKAN.

Cron: $80-72$ a. C.

Mód: 23-22 mm. Peso: 6,92 gr. Eixo: 1.

Bibl: BURGOS, 240/1505; e VILLARONGA, 212/15.

Obs: VIVES, 43/4.

7. As

A- Cabeça barbada, à direita.

Atrás, um delfim.

]£ - Ginete lanceiro, à direita.

Atrás, símbolo astral de cinco pontas.

Em baixo, inscrição ibérica BOLSKAN.

Cron: $80-72$ a. C.

Mód: 23-22 mm. Peso: 6,21 gr. Eixo: 3.

Bibl: BURGOS, 240/1505; e VILLARONGA, 212/14.

Obs: VIVES, 43/4.

Castulo

8. As

$A$ - Cabeça viril, à direita, com diadema.

À frente, mão vertical. 
tí - Esfinge, à direita.

No exergo, inscrição ibérica [KASTYLO].

Cron: Séc. II a I a. C.

Mód: 26-25 mm. Peso: 9,20 gr. Eixo: 10.

Bibl: BURGOS, 104/543; e VILLARONGA, 336/39.

Obs: MARIA PAZ GARCIA-BELLIDO, Las Monedas de Castulo..., Série VIa, grupo V (?), (165-80 a.C.).

\section{Sekaisa}

9. As

Á- Cabeça viril, à direita.

Atrás, delfim.

íi - Ginete lanceiro, à direita.

No exergo, inscrição ibérica SEKAISA.

Cron: Séc. I a. C.

Mód: 21,5 mm. Peso: 5,90 gr. Eixo: 9.

Bibl: BURGOS, 267/1685; e VILLARONGA, 236/41.

Obs: LEANDRE VILLARONGA, Numismatica Antigua de Hispania, Barcelona 1979, 181, distingue o grupo dos "dois golfinhos" nos n. ${ }^{\text {s }} 583-585$, com peso médio de 8,36 gr e cronologia da época Sertoriana.

\section{Grupo Latino}

\section{Carteia}

10. Semis

Á- Cabeça feminina, à direita, com coroa de torres.

Atrás, tridente; à frente, inscrição interna CARTEIA.

íí- Neptuno despido, de pé, à esquerda, apoiando pé direito numa rocha, com delfim na mão direita e tridente na esquerda.

À frente, $D D$.

Cron: Séc. I a.C. ao séc. I d.C.

Mód: $21 \mathrm{~mm}$. Peso: 6,68 gr. Eixo 2.

Bibl: BURGOS, 99/509-510; e VILLARONGA, 420/71.

Obs: VIVES, 129/2; e Roman Provincial Coinage, 122, com cronologias de finais do séc. I a. C. aos inícios do séc. I d. C. Também BURGOS a situa no reinado de Augusto (27 a. C. a 14 d. C.). 


\section{Corduba}

11. Quadrante

Á- Cabeça de Vénus, à direita.

Atrás, três glóbulos; à frente [CN.IVLLL.FQ].

íi - Cupido despido, de pé, à esquerda, sustendo cornucopia na mão esquerda e símbolo na direita.

À esquerda, três glóbulos verticais; à direita [CORDVBA].

Cron: Séc. II a I a. C.

Mód: 18 mm. Peso: 6,31 gr. Eixo: 6 .

Bibl: BURGOS, 249/1558; e VILLARONGA, 401/1.

Obs: VIVES, 118/1; e GIL FARRÉS, 1263 (antes de 49 a. C.).

\section{Lepida Celsa}

12. As

Á- Cabeça de Palas, à direita, com elmo.

À frente, inscrição ascendente COL.VIC.IVL.LEP.

Orla de pontos.

IÍ - Touro saltando, à direita, para investir.

Em cima PR.ILVIR; em baixo, PSALPA.M.FVLVI.

Orla de pontos.

Cron: Séc. I a. C.

Mód: 29 mm. Peso: 13,70 gr. Eixo: 6.

Bibl: BURGOS, 113/505; e VILLARONGA, 224/23.

Obs: Roman Provincial Coinage, n. ${ }^{\circ} 264$, propõe uma cronologia de 44-36 a. C., no entanto BURGOS atribue a cunhagem a 50-30 a. C.

\section{Murtiles}

13. As

$A$ - Sável, à direita.

Em cima, MVRTI[L].

]£ - Espiga, à direita.

Em cima, entre linhas $L A P D E$.

Cron: Séc. II-I a. C.

Mód: 35-33 mm. Peso: 26,87 gr. Eixo: 1.

Bibl: BURGOS, 222/1380; e VILLARONGA, 377/3.

Obs: VIVES, 109/3; e GIL FARRÉS, 1456 (47-44 a.C.).

VILLARONGA classifica esta moeda no grupo dos asses de 31,5 gr (séc. II a. C.). 


\section{Obulco}

14. As

$A$ - Cabeça feminina, à direita.

À frente, inscrição interna $O B V L C O$.

i( - As inscrições $L A I M I L$ e $M . I V N I$, ao centro e separadas por linhas.

Em cima, arado, à esquerda; em baixo, espiga, à esquerda.

À frente das inscrições, de cima para baixo [AID].

Orla de pontos.

Cron: Séc. II-I a. C.

Mód: 27 mm. Peso: 11,16 gr. Eixo: 3.

Bibl: BURGOS, 227/1414; e VILLARONGA, 348/49.

Obs: VIVES, 96/6; e GIL FARRÉS, 430 (120-90 a. C).

\section{Semis}

Á- Cabeça de Apoio, à direita.

À frente, inscrição interna $0[B] V I$.

í( - Touro, à direita.

Em cima, crescente.

Cron: Séc.I a.C.

Mód: 19-18 mm. Peso: 5,18 gr. Eixo: 3.

Bibl: BURGOS, 229/1435; e VILLARONGA, 352/81.

Obs: VIVES, 98/4 (séc. I a. C); e GIL FARRÉS, 1465 (67 a. C.).

\section{CONCLUSÃO}

Apesar de as moedas terem sido recolhidas ao longo de vários anos, o lugar da descoberta circunscreve-se a uma área de cinco metros quadrados, o que permite pôr a hipótese de pequeno ocultamento, cujo contentor seria de material perecível (tecido ou couro), ou qualquer recipiente cerâmico que charruas, arados e enxadas partiram e fragmentaram sem que fosse identificado como tal. $\mathrm{O}$ conjunto original seria maior $\left(^{6}\right)$.

${ }^{6}$ ) De modo algum pode circunscrever-se como quantitativo total, pois há seguras notícias de cerca de uma dúzia de moedas com touros e cavalos - entre outras figuras - ter sido oferecida, na Bélgica, por um emigrante de Alvorge ao patrão, por ser 
Estes numismas ocultados representam um aforro muito modesto. Todavia, revelam grande variedade de procedências, representadas por uma, duas ou três peças do mesmo tipo, sem diferente denominação.

Também elucidativo será verificar que respeitam: ao vale fértil do Ebro e do Jalon, na Celtibéria; às ricas campinas meridionais da Ulterior ou Bética; e ao Sul da Lusitânia, expressivamente documentado pelos excelentes locais situados próximo de rios, como Myrtilis, ou portos costeiros, como Bevipo, que reflectem importantes núcleos de comércio, demonstrado por estes singulares vectores da economia.

\section{BIBLIOGRAFIA}

Fontes

ARQUIVO NACIONAL DA TORRE DO TOMBO, Forais Antigos, maço 12, n 3.

PORTUGALIAE MONUMENTA HISTORICA, Leges et Consuetudines, I, Olisipone MDCCCLVL

Estudos

AlarCÃO, Jorge, A Cidade Romana em Portugal. A Formação de Lugares Centrais em Portugal, da Idade do Ferro à Romanizado, in Cidades e História, Lisboa 1992.

------, O Domínio Romano, in Nova História de Portugal. I. Portugal das Origens à Romanização, Lisboa 1990.

ARNAUT, Salvador Dias, Ladeia e Ladera, Coimbra 1939.

Burgos, Fernando Alvarez, La Moneda Hispanica desde sus orígenes hasta el siglo V, Madrid 1992.

BURnetT, A, et alii, Roman Provincial Coinage, I, London-Paris 1992.

FARIA, A. Marques de, "A Numária de Cantnipo", in Conimbriga (XXVIII), Coimbra 1989.

FARrÉS, O. Gil, La Moneda Hispanica en la Edad Antigua, Madrid 1966.

GarcíA-Bellido, Maria Paz, Las Monedas de Càstulo, in Numisma 138-143, Madrid 1976.

Gu ADAN, A. M. de, Las Monedas de Gades, Barcelona 1963.

baixo o preço que receberia numa feira numismática. Posteriormente, ouviram-se descrições de duas outras moedas com "círculos num lado e cabeça de homem no outro"; parece tratar-se do célebre escudo redondo (caetra), no reverso de asses, característico do numerário batido nos centros itinerantes que acompanhavam o exército romano quando operava no Noroeste da Hispânia, entre 26-25 a. C., durante as campanhas contra os Calaicos, Astures e Cántabros. 
Tristan, Francisca Chaves, Numismatica Antigua de la Ulterior, in Numisma 162-164, Madrid 1980.

VILlARONGA, Leandre, Corpus Nummum Hispaniae Ante Augusti Aetatem, Madrid 1994.

- Numismatica Antigua de la Hispania, Barcelona 1979.

Vives y EsCudero, A, La Moneda Hispanica, Madrid 1924-1926.

Conimbriga, 34 (1995) 191-204 


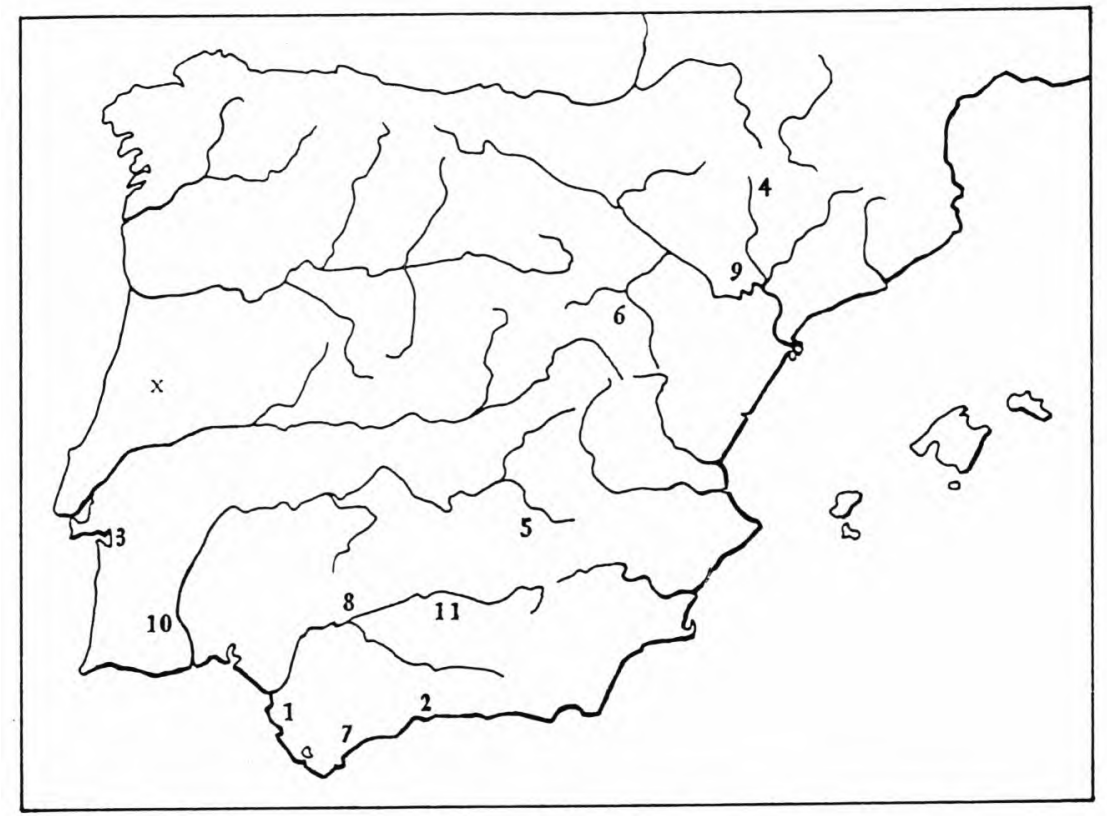

Localização dos centros emissores representados no achado monetário

X Monte Figueiró

1 Gades

2. Maláca

3. Bevipo
4. Bolskan

5. Castulo

6. Sekaisa

7. Carteia
8. Córduba

9. Lépida Celsa

10. Murtiles

11. Obulco 